\title{
polyhomeotic: a gene required for the embryonic development of axon pathways in the central nervous system of Drosophila
}

\author{
David Smouse, ${ }^{1,3}$ Corey Goodman, ${ }^{1,4}$ Anthony Mahowald, ${ }^{2}$ and Norbert Perrimon ${ }^{2,3}$ \\ Department of Biological Sciences, Stanford University, Stanford, California 94305 USA; ${ }^{2}$ Department of Developmental \\ Genetics and Anatomy, Case Western Reserve University, Cleveland, Ohio 44106 USA
}

\begin{abstract}
Hypomorphic alleles of the locus polyhomeotic (ph) produce multiple, homeotic-like transformations in adult flies that mimic dominant mutations in the Antennapedia and Bithorax complexes. Analysis of null alleles of $p h$ has revealed a complex, embryonically lethal phenotype that includes cell death of the ventral epidermis and abnormalities in the patterns of expression of homeotic and segmentation genes. There is also a dramatic alteration in the pattern of axon pathways in the central nervous system, such that the wild-type array of segmentally repeated commissures and connectives is replaced by bundles of axons confined to the hemiganglia of origin. It is possible that this axonal phenotype is the result of loss of neuronal identity caused by abnormal homeotic and segmentation gene expression.
\end{abstract}

[Key Words: polyhomeotic; Drosophila; axon pathways; central nervous system; segmentation]

Received January 29, 1988; revised version accepted May 13, 1988.

The embryonic epidermis of Drosophila is segmented and secretes a series of segment- and compartment-specific cuticular structures, which have served as the substrate for the identification and analysis of mutations in genes controlling pattern formation. Systematic screens for loci required during embryonic development have identified a limited number of genes that are involved in the process of segmentation (Nüsslein-Volhard and Wieschaus 1980; Jürgens et al. 1984; Nüsslein-Volhard et al 1984; Wieschaus et al. 1984) or that determine segmental identity (Lewis 1978; Kaufman 1983). The latter class, the homeotic genes, appear to interact with a third group of loci, the Polycomb $(P C)$ group (Lewis 1978; Struhl 1981; Duncan 1982; Dura et al. 1985; Jürgens et al. 1985) which, when mutated, produce homeotic transformations.

The embryonic nervous system is also segmented, contains identifiable cells in characteristic positions, and has segment-specific differences (Thomas et al. 1984; Ghysen et al. 1986). Based on these similarities, one might expect similar mechanisms to govern the development of the epidermis and the nervous system. However, there is experimental evidence that fundamentally different principles apply during nervous system development. The development of the epidermis and its cuticular derivatives is largely cell autonomous (Garcia-Bellido and Lewis 1976; Morata and Garcia-Bel-

${ }^{3}$ Present address: Howard Hughes Medical Institute, Department of Genetics, Harvard Medical School, Boston, Massachusetts 02115 USA. 'Present address: Department of Biochemistry, University of California, Berkeley, California 94720 USA. lido 1976; Gergen and Wieschaus 1985, 1986). In contrast, the development of the insect nervous system has been shown to be the result of both specific and invariant cell lineages, as well as complex cell-cell interactions (Doe and Goodman 1985a,b; Kuwada and Goodman 1985). Interactions occur between presumptive neuroblasts and the surrounding ventral epithelial cells during the birth of neuroblasts (Doe and Goodman 1985b). Later in development, the neuronal progeny of these neuroblasts extend growth cones that navigate along stereotyped pathways to specific targets and, in so doing, must again interact with epithelial cells, glial cells, extracellular substrates, and other neurons (Goodman et al. 1984).

We have initiated a screen for zygotic lethal mutations that affect the development of the embryonic central nervous system (CNS). A large number of lethal loci produce defects and disorganization in the nervous system; however, only a small number have been found so far that cause defects that are consistent and reproducible from segment to segment and from embryo to embryo. Mutations in one such gene, polyhomeotic (ph), affect the development of axon pathways in the embryonic CNS. As its name suggests, $p h$ also belongs to the class of genes required for the normal function of homeotic loci.

Results

Genetics of ph

Flies homo- or hemizygous for the original alleles of the $\mathrm{X}$-linked locus, $p h(2 \mathrm{D} 3-4)$, are viable and have multiple, 
allele-specific homeotic transformations of adult cuticular structures (Dura et al. 1985, 1987; Perrimon et al. 1985). In particular, meso- and metathoracic legs are partially transformed to the prothoracic leg, and wing can be partially transformed into haltere. These phenotypes are similar to those produced by the dominant $P C$ (Denell 1978) and Contrabithorax mutations (Lewis 1978), respectively. In addition, ph males exhibit a phenotype similar to that produced by the mutation Miscadestral pigmentation (Lewis 1978). All viable alleles of $p h$ are hypomorphic in character, whereas a deficiency, $D f(1) I A 52$, which removes the $p h$ locus, is amorphic and embryonic lethal when hemizygous in males (Perrimon et al. 1985). Recent molecular evidence (Dura et al. 1987) has suggested that the $p h$ locus represents a tandem duplication of a transcription unit such that a mutation in a single copy produces the hypomorphic phenotype, whereas mutating or deleting both copies produces the embryonic lethal phenotype. A double mutant, $p h^{505}$ (Dura et al. 1987), was generated by mutating to lethality a chromosome carrying a hypomorphic allele of $p h$ and has been generously supplied by J.-M. Dura. The embryonic phenotypes produced by the double mutant and the deficiency are identical, and the results reported here were obtained with both genotypes; thus, we do not generally distinguish between genotypes in the text, but refer to embryos carrying either of the null mutations as ph- embryos.

\section{Epidermal phenotype of $\mathrm{ph}^{-}$embryos}

Male embryos hemizygous for the double mutant $p h^{505}$, or the deficiency $D f(1) I A 52$, exhibit a variety of developmental defects. The ventral epidermis begins dying 9.5 $\mathrm{hr}$ after egg laying, and death of these cells starts at the anterior and posterior poles and spreads toward the middle of the embryo. By $12 \mathrm{hr}$, all epidermal cells ventral to the tracheal pits have died and sloughed off, exposing the ventral nerve cord (Figs. 1d and $2 c, d$ ). As a result of this cell death, embryos at $22 \mathrm{hr}$ of development have a large hole in the ventral cuticle of the thoracic and abdominal segments (Fig. 1c). In a small fraction of embryos, there is some surviving ventral epidermis, which is generally in the middle of the embryo and which is capable of secreting naked cuticle.

There are apparent abnormalities in segmentation as well, but these are difficult to analyze because of the missing ventral cuticle. The head, however, is clearly abnormal (Fig. 2a,c) and appears to be composed of several fused and transformed segments. The distal portions of the labial lobes do not meet at the midline, nor do they rotate and fuse, as in wild-type embryos (Turner and Mahowald 1979). The salivary gland openings form (Fig. 2c) but do not meet and fuse. The dorsal indentation in the maxillary appendage is evident in $\mathrm{ph}^{-} \mathrm{em}-$ bryos, but is not carried anteriorly because head involution does not take place. Without suitable landmarks, it is difficult to follow development of the antennal and mandibular appendages in $p h^{-}$mutants, though it appears that these form abnormally, resulting in a head that is broader than normal. These defects may be due to the failure of head involution or to a direct effect of the ph mutation; evidence presented below suggests that there are transformations of head segments in $\mathrm{ph}^{-} \mathrm{em}-$ bryos.

\section{Nervous system phenotype of $\mathrm{ph}^{-}$embryos}

Antisera against horseradish peroxidase (anti-HRP) recognize epitopes on the surfaces of all cell bodies and axons of Drosophila neurons (Jan and Jan 1982; Snow et al. 1987). This antisera has been useful as a probe for identifying and following the development of embryonic neurons. At $10 \mathrm{hr}$, wild-type neurons begin sending growth cones in characteristic and stereotyped fiber tracts that result, by $12 \mathrm{hr}$, in a ladderlike arrangement of axons (Fig. 3a), which lie dorsal to the neuronal cell bodies. For each segment this ladder is composed of two commissures that contain axons crossing horizontally within a segment, as well as longitudinal fiber tracts that run anteroposteriorly and extend between segments. Axons of motor neurons exit the CNS and extend into the peripheral tissues through the intersegmental and segmental nerves. Sensory neurons lie in identifiable clusters in the periphery and send axons ventrally, also along stereotyped fiber tracts which meet and, in some cases, fasciculate with the dorsally directed axons of motor neurons (Campos-Ortega and Hartenstein 1985; Ghysen et al. 1986).

Male embryos hemizygous for $p h^{505}$ or $D f(1) J A 52$ show a remarkable alteration in axonogenesis. Axons from CNS cell bodies extend dorsally but rarely extend between segments or cross within a segment; rather, these axons form conspicuous bundles or whorls within the center of each hemiganglion (Fig. 3b,c). The formation of axon bundles occurs concomitantly with the onset of cell death of the ventral epidermis, and it is possible to find neuromeres containing bundles which are covered by patches of apparently normal, yet transiently viable, epidermis. The bundles enlarge as more axons are added during neurogenesis, and fusions of adjacent bundles are observed (Fig. 3c). Occasionally, a few axons are also observed to cross within or between segments in the CNS; these axons are CNS derived as they are labeled with a monoclonal antibody (A. Bieber and C. Goodman, unpubl.) that recognizes only CNS axons and not those of the sensory neurons. These escaping axons are only seen in older embryos, and it is possible that they do not escape from the bundles until the arrival of the sensory neurons (see below). The pattern is disrupted further by a characteristic shortening of the embryo and, at later stages, by herniation of the gut through the ventral nerve cord. The fusions of bundles may be due to the escaping axons; alternatively, the fusions and the shrinkage of the embryo may be consequences of normal nerve cord condensation.

The characteristic and precise pattern of peripheral nervous system (PNS) cell types seen in the wild-type embryo (Ghysen et al. 1986; Fig. 4a) is replaced by small clusters of unidentifiable neurons in $p h^{-}$embryos. 

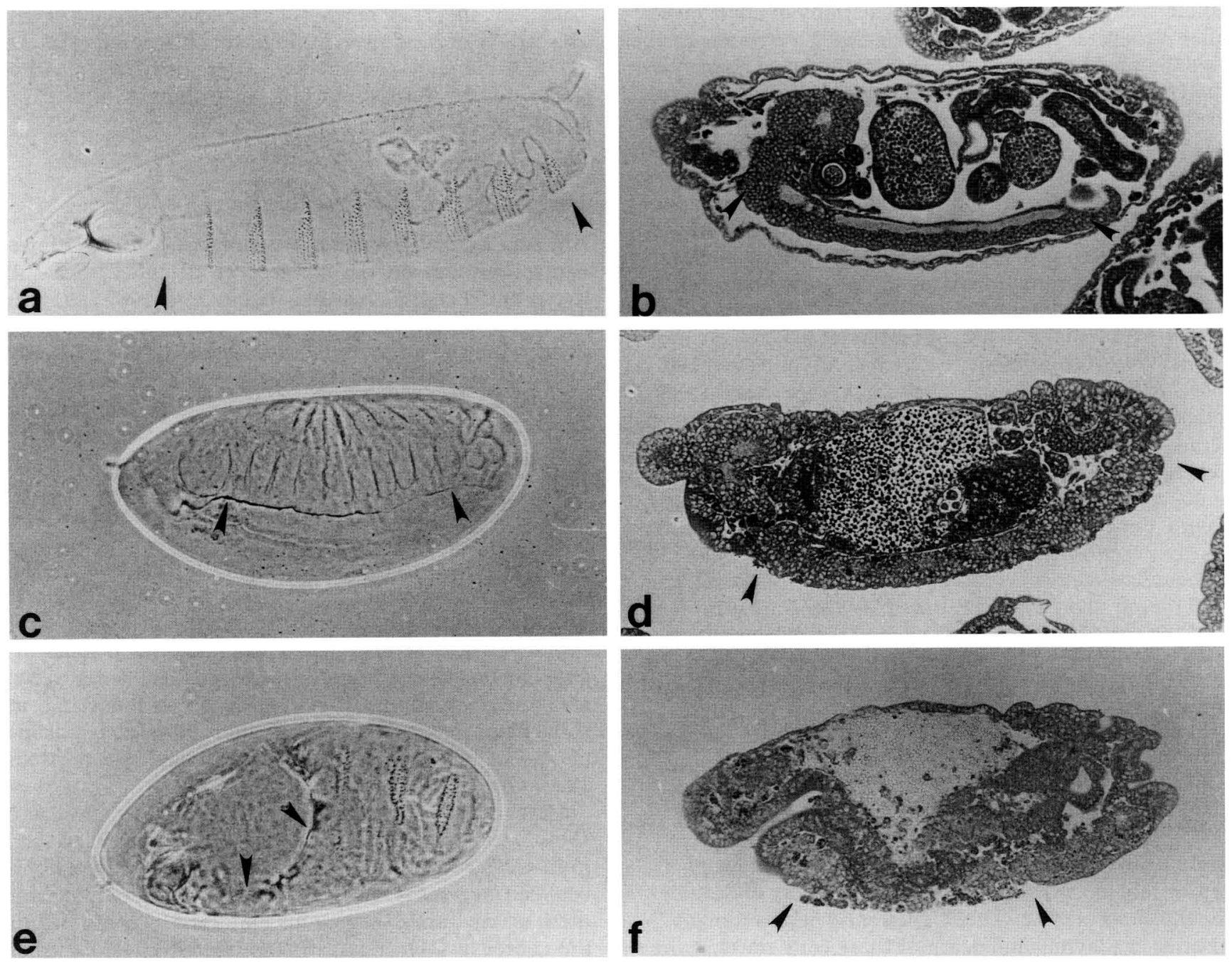

Figure 1. Cuticular and epidermal defects in $p h^{-}$embryos. (Anterior is to the left in all panels.) Cuticle $(a)$ and longitudinal section (b) of wild-type embryos. $(a)$ The arrowheads point to the ventral denticle bands of segments $\mathrm{T} 3$ and $\mathrm{A} 8$; $(b)$ the arrowheads indicate the anterior and posterior ends of the ventral nerve cord of a 14-hr embryo. Magnification, $140 \times(a)$. (c,d) Cuticle and section of embryos hemizygous for $D f(1) J A 52$. There is a large hole marked with arrowheads in the ventral cuticle of the embryo in $c$ and a corresponding hole in the ventral epidermis of an 11- to 12-hr embryo in $d$. (e,f) Cuticle and section of embryos derived from homozygous $\mathrm{ph}^{-}$germ-line clones. In both cases, there is a large hole in the anterior region of the embryo, indicated by arrowheads. (e) Two to three segments in the posterior region have denticle bands; $(f)$ an analogous region of epidermis remains viable.

These cells are clearly PNS neurons, based on their lateral location and on their staining with the SOX2 monoclonal antibody (Goodman et al. 1984), and some of these neurons even extend axons ventrally, which find their way to the CNS (Fig. 4b). However, the identity (e.g., chordotonal, numerous dendrite, or external sensory) of these neurons cannot be determined because of their abnormal organization. These abnormalities may be associated with transformations of segmental or neuronal identity.

Transmission electron microscopy of $\mathrm{ph}^{-}$embryos has revealed that the cells of the CNS are, in fact, viable as late as $14 \mathrm{hr}$ even though they are no longer covered by ventral epidermis. Although a small number of necrotic cells are observed in the CNS at this time, they are no more abundant in $\mathrm{ph}^{-}$embryos than in wild-type embryos. Furthermore, the morphology of the CNS cells, albeit their short axons, and the growth cones and filopodia associated with these processes are all normal in ultrastructure (data not shown).

A monoclonal antibody that recognizes glial- and neural-specific antigens (N.H. Patel, R. Jacobs, and C. Goodman, unpubl.) was used to analyze the pattern of glia in $\mathrm{ph}^{-}$mutants. This monoclonal antibody stains a glial sheath surrounding the ventral nerve cord and the segmental nerves, as well as staining more faintly all epidermal cell membranes in 12 to 13-hr wild-type embryos. $p h^{-}$embryos of the same stage lack this sheath, although the lateral epidermis continues to stain. This suggests that the presumptive glioblasts fail to form, 

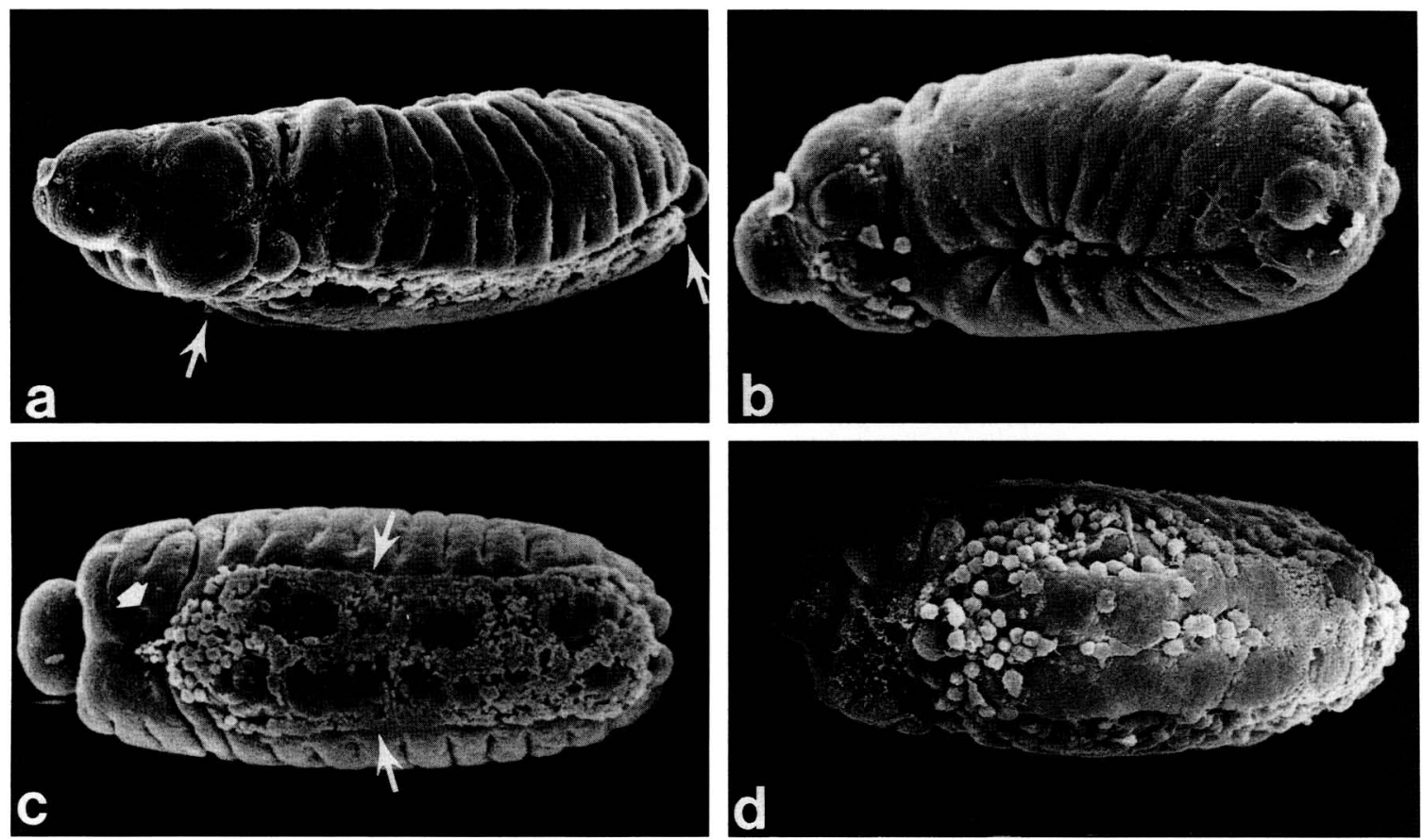

Figure 2. Scanning electron micrographs of $p^{-}$embryos. Magnification, $180 \times,(a)$ Side view of an 11-hr embryo in which the ventral epidermis from $\mathrm{T} 1$ to A8 has died (arrows). The lateral epidermis is clearly segmented and nearly normal in appearance, but the head is broad and abnormally shaped. (b) Dorsal view of a 12-hr embryo showing the abnormally shaped head and the small dorsal hole, which is the result of incomplete dorsal closure. This defect in dorsal closure apparently results in the radial appearance of the segmental grooves that are evident here and in Figure 1c. Ventral views of 11-hr $(c)$ and 12-hr $(d)$ embryos; in both cases, the ventral epidermis has died, exposing the ventral nerve cord. $(c)$ The demarcation between viable, lateral epidermis and necrotic, ventral epidermis is characteristically sharp and indicated by small arrows. The salivary gland opening is indicated by a large arrow.
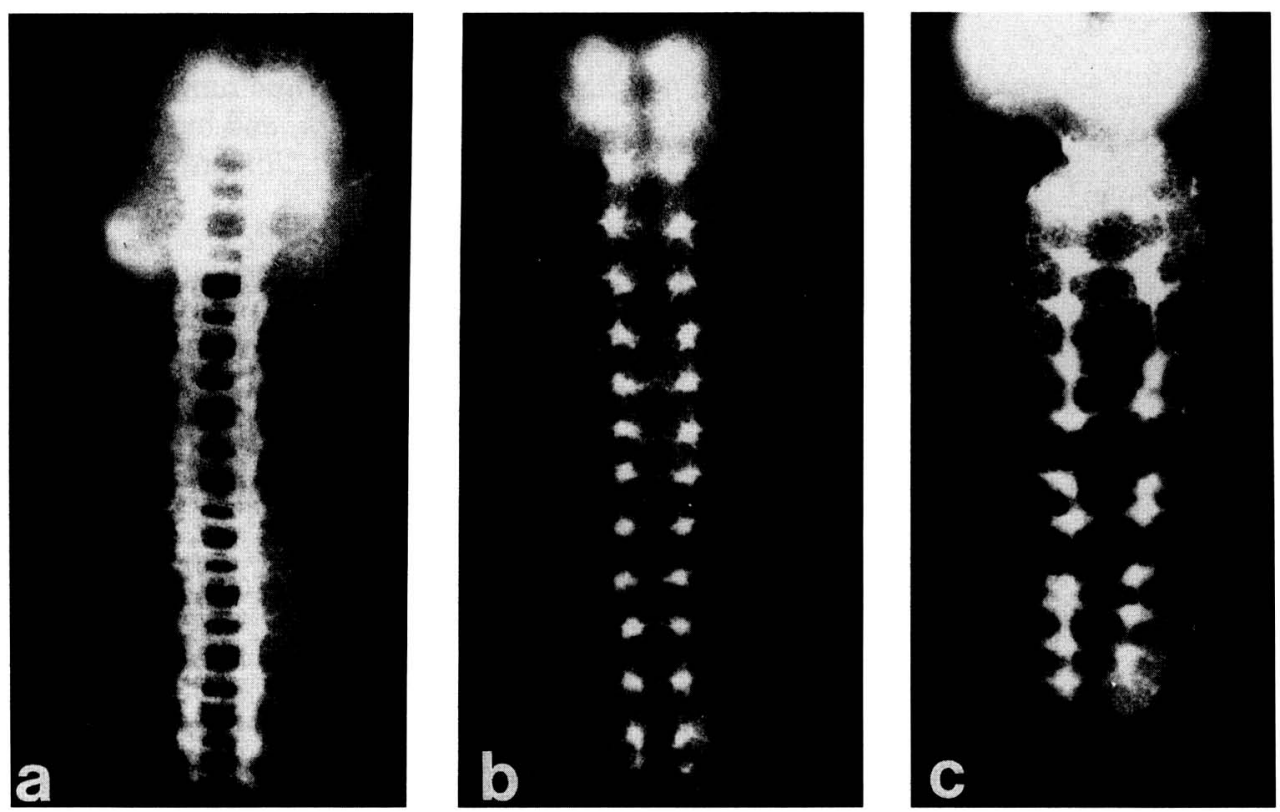

Figure 3. CNS phenotype of $p h^{-}$embryos. Embryos were stained with FITC-conjugated anti-HRP antisera. (Anterior is to the top in all panels.) Magnification, $188 \times$. (a) Wild-type embryo at $13 \mathrm{hr}$, showing the characteristic axon ladder composed of horizontal commissures and longitudinal connectives. (b) A ph- embryo at $11 \mathrm{hr}$ in which pairs of axon bundles replace the pairs of commissures and longitudinals seen in each segment of the wild-type CNS. (c) A ph- embryo at $13.5 \mathrm{hr}^{-}$nerve cord condensation is taking place and there is fusion of adjacent bundles along the longitudinal axis. A small number of axons cross horizontally within, and longitudinally between, segments. 
that they form but fail to divide, or that they divide but, like the ventral epidermis, die during embryogenesis.

\section{Homeotic gene expression in $\mathrm{ph}^{-}$embryos}

The adult phenotypes associated with viable, hypomorphic alleles of $p h$ suggest that the gene interacts with homeotic loci. To test this and to characterize further the CNS phenotype, antibody probes that recognize the protein products of the Sex combs reduced $(S c r)$, Antennapedia $(A n t p)$, and Ultrabithorax $(U b x)$ genes were used to analyze their patterns of expression in $\mathrm{ph}^{-} \mathrm{em}$ bryos. Wild-type embryos stained for Scr-gene products show $S c r$ expression in epidermal cells of the labial lobe, or S3, and in the anterior compartment of $\mathrm{T} 1$ (data not shown; Riley et al. 1987). This pattern of expression is in good agreement with the domain of action of Scr predicted from mutant phenotypes (Wakimoto and Kaufman 1981; Sato et al. 1985). As head involution takes place, the labeled epidermis is carried anteriorly and becomes the ventral part of the atrium. At the same time, cells of the CNS associated with the labial lobe
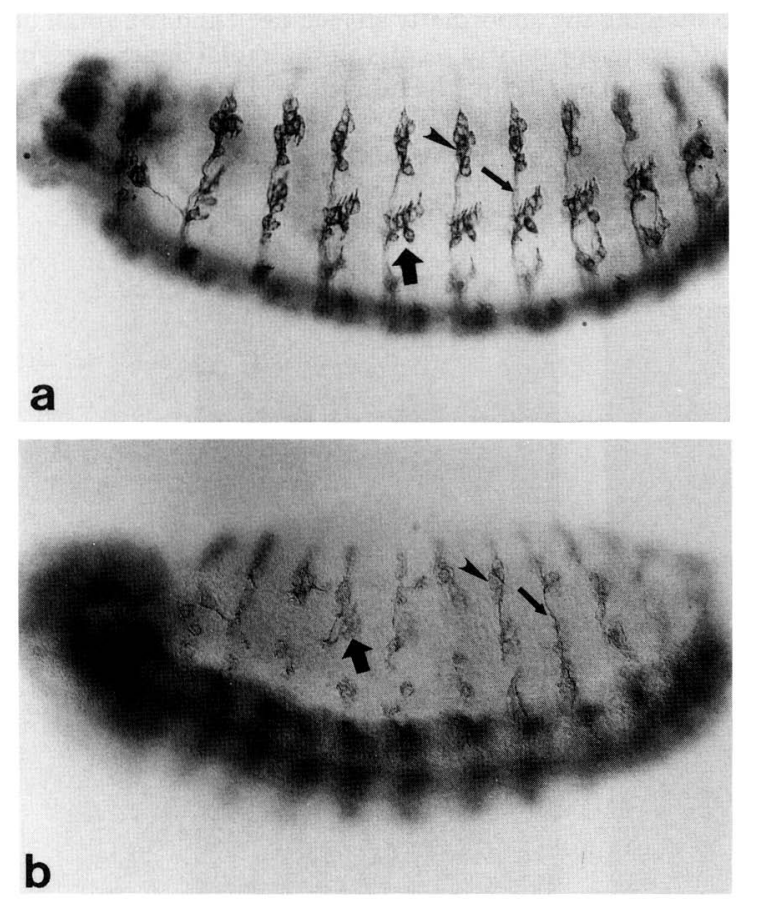

Figure 4. PNS of wild-type and $\mathrm{ph}^{-}$embryos. (a) Wild-type embryo stained with a monoclonal antibody that recognizes all sensory neuron cell bodies and their neurites (Goodman et al. 1984). The large arrow points to cells of the lateral cluster of A2, the arrowhead points to cells of the dorsal cluster of A3, and the small arrow indicates the ventrally directed nerve-containing axons from the dorsal cluster of A4. (b) A ph- embryo stained with the same monoclonal antibody. The precise array of peripheral neurons is not present in $p^{-}$embryos, but it is possible to identify cells of the lateral (large arrow) and the dorsal (arrowhead) clusters and to demonstrate that some of these neurons extend axons ventrally to the CNS (small arrow). and $\mathrm{T} 1$ stain intensely with the antisera (Fig. 5a), indicating high levels of $S c r$ expression in neurons derived from the same region as the labeled epidermis. In contrast to Antp and $U b x$, there appear to be few, if any, $S c r$-positive neurons in segments posterior to the most intensely labeled segment. Wild-type patterns of Antp (Carroll et al. 1986; Wirzet al. 1986) and Ubx expression (White and Wilcox 1984, 1985a, 1985b; Beachy et al. 1985) are complex both spatially and temporally, and have been described in detail. Briefly, Antp is expressed in the epidermis of posterior $\mathrm{T} 1$, all of $\mathrm{T} 2$, and most of T3. It is also found in regions of the CNS of the corresponding segments, and in a smaller subset of CNS cells in anterior $\mathrm{Al}-\mathrm{A} 7 . \mathrm{Ubx}$ is expressed at high levels in the epidermis and CNS of posterior T3 and anterior A1, and at somewhat lower levels in $\mathrm{T} 2$, posterior $\mathrm{T} 3$, and anterior A2-A7.

The normal patterns of expression of these homeotic genes are radically altered in $\mathrm{ph}^{-}$embryos; these alterations depend on the particular homeotic gene, the embryonic stage, and the tissue (epidermis or CNS) being analyzed. The epidermal expression of these genes will be considered first. There are two, and sometimes three, segments or parts of segments expressing $S c r$ in the epidermis of the anterior region of $p h^{-}$embryos (Fig. 5d). The ectopic expression could represent a transformation of segment identity resulting in a duplication or triplication of the labial lobe. The lower sensitivity of the Antp antisera did not permit detection of epidermal expression of Antp gene products in either wild-type or $\mathrm{ph}^{-}$ embryos. No defects in the pattern of $U b x$ expression are observed in the epidermis of embryos prior to germband retraction. However, Ubx expression is clearly abnormal in $p h^{-}$embryos following germ-band retraction; in these embryos, epidermal cells in segment T1-A7 express relatively low and uniform levels of $U b x$. This expression is transient, and by $13 \mathrm{hr}$ there is no immunologically detectable $U b x$ protein in the surviving lateral epidermis.

The most striking effect on homeotic gene expression in $p h^{-}$embryos is in the CNS, where there appears to be no detectable $S c r, A n t p$, or Ubx expression (Fig. 5d-f) at $13 \mathrm{hr}$. At this time, wild-type embryos exhibit high levels of CNS expression of all three genes (Fig. $5 a-c)$. It is possible that transient homeotic gene expression may occur in the CNS of $p^{-}$embryos during germ-band retraction; this is difficult to assess because the levels are low even in wild-type embryos at this stage and are masked somewhat by the high levels of epidermal expression. However, by the time germ-band retraction has been completed (by $10 \mathrm{hr}$ ), there are no immunologically detectable protein products of these three homeotic genes in the CNS of $p h^{-}$embryos.

\section{Segmentation gene expression in $\mathrm{ph}^{-}$embryos}

There is evidence that the homeotic genes are directly or indirectly regulated by the segmentation genes (for review, see Akam 1987). It has also been shown that at least some of the segmentation genes are expressed in the embryonic CNS. To determine whether the ab- 
normal patterns of homeotic gene expression observed in $\mathrm{ph}^{-}$embryos are the consequence of alterations in segmentation gene expression, $p h^{-}$embryos were stained with antisera specific for the gene products of the pair-rule genes fushi tarazu (ftz) (Carroll and Scott 1985) and even-skipped (eve) (Frasch et al. 1987) and the segment-polarity gene engrailed (en) (DiNardo et al. 1985). en expression is normally seen in the posterior epidermal compartments of all segments, as well as in a subset of CNS neurons (Fig. 6a). The epidermal pattern is established early in embryogenesis and is apparently normal in $\mathrm{ph}^{-}$embryos prior to germ-band retraction. As development proceeds, the expression of en in the epidermis changes in $\mathrm{ph}^{-}$embryos; by $11 \mathrm{hr}$, the level of expression of en declines in the posterior compartments of the thoracic and abdominal segments and, at the same time, becomes detectable at low levels in the anterior compartments. There are also abnormal patterns of expression in the heads of $\mathrm{ph}^{-}$embryos (Fig. 6b), where en appears to be expressed at relatively high and uniform levels throughout both compartments of at least three head segments, which also correspond to those cells positive for Scr. As with the homeotic genes described above, there is no en protein in the CNS of $\mathrm{ph}^{-}$embryos by $12-13 \mathrm{hr}$. Earlier en expression in the CNS, including expression in neuronal precursor cells and in the first progeny of the median neuroblast, is normal.

The temporal and spatial patterns of $f t z$ and $e n$ expres-
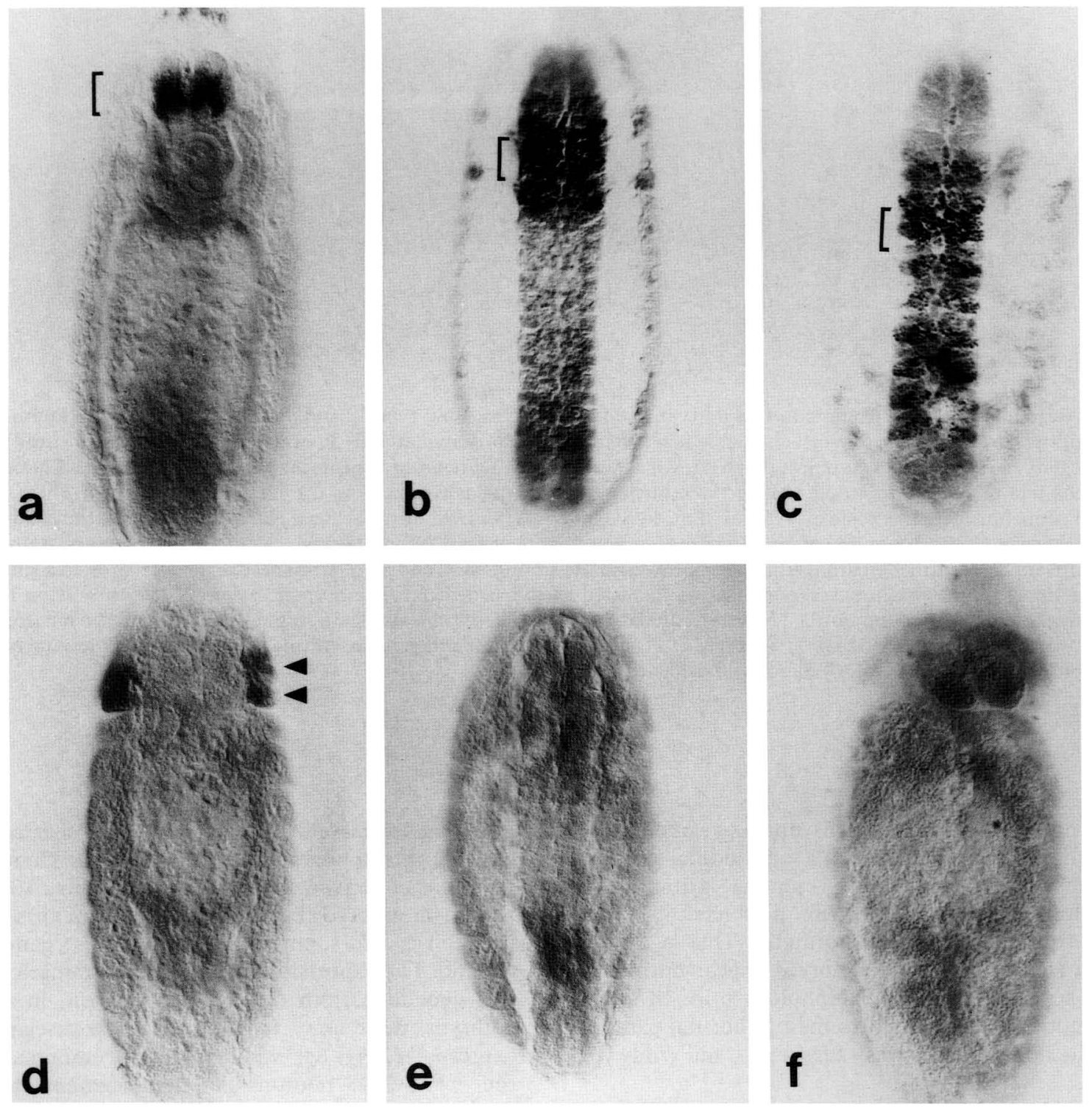

Figure 5. Homeotic gene expression in wild-type and $p h^{-}$embryos. Ventral views of 13-hr wild-type $(a-c)$ and $p h^{-}(d-f)$ embryos stained with antibodies to $S c r(a, d), A n t p(b, e)$, and $U b x(c, f)$. The most intensely labeled wild-type segments are indicated by brackets; these are S3 for $S c r(a), \mathrm{T} 2$ for $A n t p(b)$, and Al for $U b x(c)$. Note the complete absence of antibody staining in the CNS of all three $p h^{-}$ embryos. The Scr-labeled epidermal patches are indicated by arrowheads in $d$; there is often a third patch that is more dorsal and anterior and is not visible in this plane of focus. Magnification, $200 \times$. 

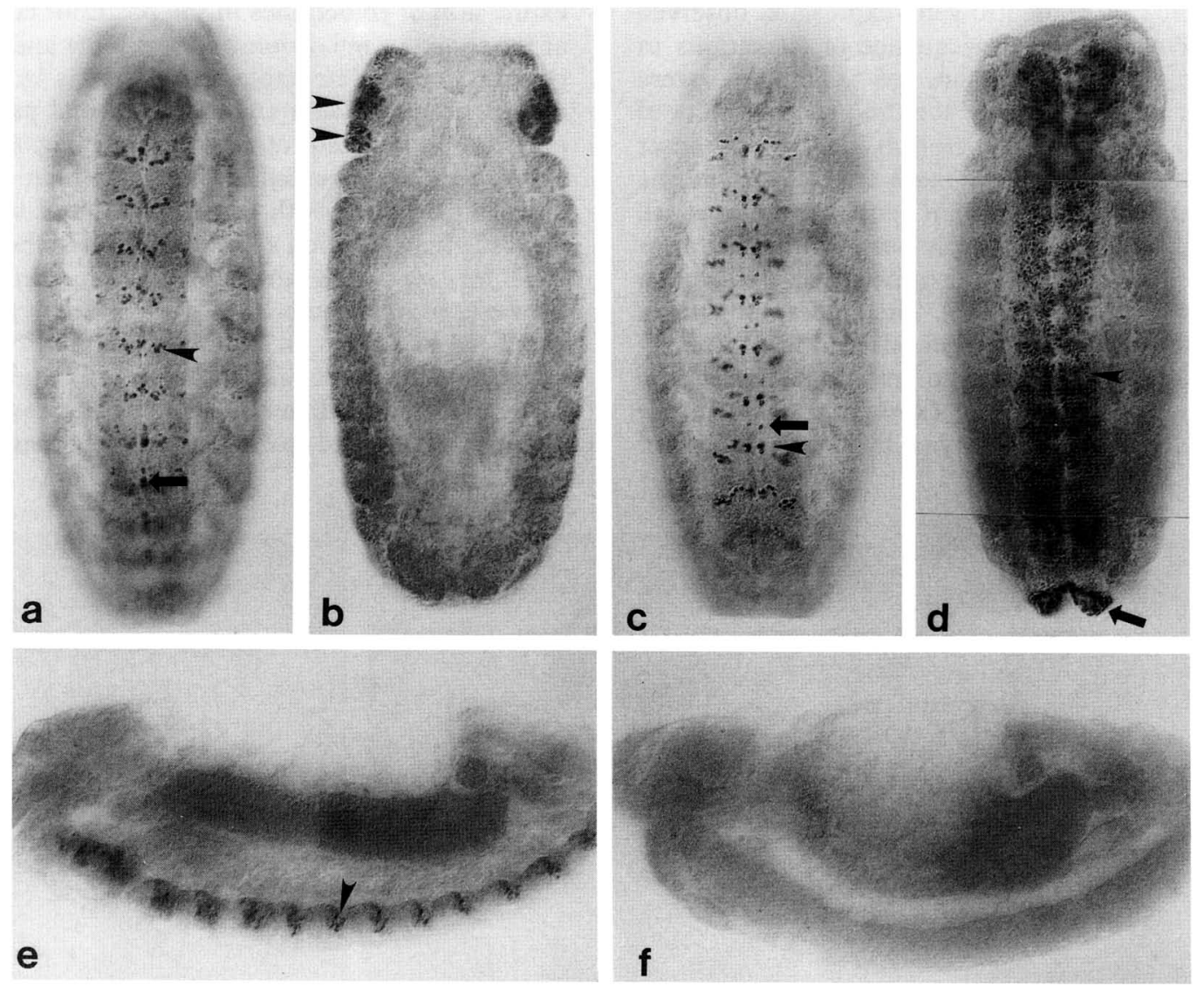

Figure 6. Segmentation gene expression in wild-type and $p h^{-}$embryos. Wild-type $(a)$ and $p h^{-}(b)$ embryos stained with an anti-en antisera. $(a)$ en is expressed in a five-cell cluster, which is found posteriorly and laterally in every hemisegment (arrowhead) and in the ventral progeny of the median neuroblast (large arrow), as well as in other neurons. This focal plane emphasizes the CNS expression, but it is possible to see a thin stripe, two to three nuclei wide, of en-positive cells in the lateral epidermis. $(b)$ There is no CNS expression of $e n$, but there is ectopic expression in the head epidermis (arrowheads). The focal plane demonstrates the head expression and the absence of expression in the anterior and posterior segments of the CNS. Wild-type $(c)$ and $\mathrm{ph}^{-}(d)$ embryos stained with an anti-eve antisera. (c) Identified neurons RP2 (large arrow) and the siblings aCC and pCC (arrowhead) express eve, as do a small number of other neurons; $(d)$ many neurons express eve, as indicated by the arrowhead. The normal pattern of eve expression in the cells surrounding the anal pads is unperturbed by loss of $p h$ (large arrow). These cells also stain in the wild-type embryo but are not in the field of view in $c$. Wild-type $(e)$ and $p h^{-}(f)$ embryos at $11 \mathrm{hr}$ stained with an anti-ftz antisera and shown in lateral view. $(e)$ Neurons are clearly expressing $f t z$ (arrowhead); ( $f$ ) there is no evidence of $f t z$.

sion are normal in $\mathrm{ph}^{-}$embryos during segmentation when both genes are expressed in a longitudinal series of seven transverse stripes that represent the primordia of every other segment. Both gene products disappear during germ-band elongation normally. This is consistent with the fact that $p h^{-}$embryos appear normal in terms of segmentation and morphology prior to germband retraction. The cells surrounding the anal pad and cells at the dorsal rim express $e v e$ in $p^{-}$and wild-type embryos.

Both $f t z$ (Carroll and Scott 1985; Doe et al. 1988) and eve (Frasch et al. 1987; C.Q. Doe and D. Smouse, unpubl.) are expressed in distinct patterns in the wild-type CNS that are different from one another and from their expression in the ectoderm during segmentation. Both genes are expressed in a discrete subset of neuronal nuclei in a pattern repeated in each segment. There are $>30$ neurons per hemisegment expressing $\mathrm{ftz}$ in a 10- to 11 -hr wild-type embryo (Fig. 6e), and much of this CNS expression is also suppressed by loss of $p h^{+}$gene product (Fig. 6f). The expression of eve departs dramatically from this general pattern of CNS suppression; in wild-type embryos, there are $\sim 16$ neurons per hemisegment that express eve (Fig. 6c), whereas in ph- $^{-}$embryos, most of the $\sim 250$ CNS neurons per hemisegment stain positively for eve (Fig. 6d). Ectopic expression of eve is observed in the brain as well as in the ventral nerve cord. Small clusters of eve-positive cells are also observed laterally; these may indicate ectopic eve expression in neurons of the PNS. 
The $\mathrm{ph}^{-}$gene is required for the normal function of the cis-acting control elements of en and $\mathrm{ftz}$

The fusion of the cis-acting regulatory elements of the en (C. Hama and T. Kornberg, pers. comm.) and $f t z$ (Hiromi and Gehring 1987) genes to the coding sequences for $l a c Z$ confer onto $\beta$-galactosidase the spatial and temporal patterns of expression appropriate to the donor gene. The effects of $p h$ on en and $f t z$ regulatory regions were examined by introducing null mutations for $p h$ in flies stably transformed with $e n-l a c Z$ and $f t z-$ lac $Z$ fusion genes. The expression of $\beta$-galactosidase in the epidermis of $\mathrm{ph}^{-}$; en-lacZ embryos is consistent with the pattern of expression of the native en protein. Early $p h^{-}$embryos have a normal pattern of expression, whereas later embryos show low levels of ectopic expression in the anterior compartments of segments T1-A8 (cf. Fig. 7, b and a). There are also high levels of $\beta$-galactosidase expression in the head. These results suggest that en-gene expression is affected by $p h^{-}$at the level of transcription. Unlike the native en protein, there does appear to be $\beta$-galactosidase expression in the CNS of older $p h^{-}$embryos; however, this is probably due to perdurance of $\beta$-galactosidase that is synthesized in the ectodermal precursors of the CNS cells prior to neurogenesis.

The early patterns of $\beta$-galactosidase expression are also normal in $\mathrm{ph}^{-}$; ftz-lacZ embryos (Fig. 7c). Thus, the seven epidermal stripes are clearly evident and can be followed throughout development because of the perdurance of $\beta$-galactosidase. Interestingly, the first neuronal precursor cells that normally express $\beta$-galactosidase in wild-type; ftz-lac $Z$ embryos (the midline precursors 2 or MP2s; Doe et al. 1988) also express $\beta$-galactosidase in $p h^{-}$;ftz-lacZ embryos. However, by $13 \mathrm{hr}$, there are many neurons expressing $\beta$-galactosidase in wild-type embryos (Fig. $7 \mathrm{~d}$ ), whereas there are no new neurons expressing it in $p^{-}$embryos. The MP2s continue to be labeled by $\beta$-galactosidase in older $p h^{-}$embryos as well (Fig. 7e); again, this is most likely due to perdurance of $\beta$-galactosidase synthesized earlier. This labeling allows the MP2s to be followed during development and demonstrates that they do not undergo their single and terminal division in $\mathrm{ph}^{-}$embryos.

\section{Maternal effect of ph}

A number of loci exhibit phenotypes that are either more severe or different when there is loss of gene function from the maternal germ line compared to loss of gene function zygotically. The maternal effect of $p h$ was examined by inducing homozygous $p h^{-}$germ-line clones in female flies heterozygous for $p h^{505}$ and the dominant female sterile mutation ${ }^{O V O} \mathrm{O}^{D 1}$. Females heterozygous for $O{ }^{2} O^{D 1}$ produce no eggs, and any eggs produced by heterozygous females following irradiation during larval stages (see Experimental procedures) will be derived from germ-line clones that are homozygous for $p h^{505}$. The phenotype of eggs derived from such germ-line clones and fertilized by wild-type sperm is shown in Figure 1, e and $f$. There is a partial rescue of the epidermal cell death because several segments secrete ventral cuticle. The anterior and posterior midgut form, but the gut itself is misshapen and smaller than normal. Very little CNS tissue develops, and it is severely disorganized. The strong phenotype indicates that there is a requirement for $p h$ in the female germ line.

A second class of embryos derived from $p h^{505}$ germline clones was also observed. These embryos are poorly differentiated, secrete only small, disorganized patches of cuticle, and appear abnormal as early in development as gastrulation. It is assumed that the first class of partially rescued embryos represents female embryos that have received a wild-type copy of $p h$ from sperm and thus have $p h$ expressed zygotically, whereas the second class represents male embryos that lack ph maternally and zygotically. Support for this assumption comes from the fact that the mutation yellow is linked to $p h$ and would cause denticles to appear yellow in male $\left(y \mathrm{ph}^{505} /\right.$ $\mathrm{Y})$ embryos. However, none of the partially rescued embryos produce yellow denticles, indicating that they are genotypically y $\mathrm{ph}^{505} /+$.

Finally, a large number of $p h^{-}$germ-line clone-derived eggs appear unfertilized and fail to develop. It is not clear whether these eggs represent the usual background of abnormal oocytes produced by germ-line clones or whether they indicate a function of $p h^{+}$during oogenesis in addition to the function during embryogenesis of maternally stored gene product.

\section{Discussion}

Loss of function of $p h$ locus results in a complex, pleiotropic phenotype that includes cell death of the ventral epidermis, abnormal patterns of homeotic and segmentation gene expression, abnormal axonal guidance in the CNS, and embryonic lethality. Germ-line clones also indicate that $p h$ is required in the female germ-line for normal embryonic development. It is not possible at this time to determine which aspects of the phenotype are directly caused by loss of $p h$ gene function(s) and which are only secondary to it. The pleiotropic phenotype is complicated further by the apparent complexity of the locus at the molecular level. There are two homologous transcription units at the ph locus (Dura et al. 1987), and removal of both results in the amorphic phenotype. It is not clear whether loss of one unit is sufficient to produce all of the phenotypes, whether the two units are functionally equivalent, or whether the transcription units perform overlapping but not identical functions. Several other loci, including achaete-scute (Villares and Cabrera 1987), gooseberry (Baumgartner et al. 1987), and en (Coleman et al. 1987), have been found to be closely linked to homologous transcription units, suggesting that the physical association of potentially functionally related genes is not unique.

The abnormal nervous system phenotype of embryos lacking $p h$-gene activity suggests that this gene is involved, directly or indirectly, in the establishment of the normal pattern of axon pathways in the embryonic CNS. 
Figure 7. Expression of en-lacZ and $f t z-l a c Z$ genes in wild-type and $p h^{-}$embryos. (Anterior is to the top in $a-e \mid$; ventral is to the left in $a$ and $b .\langle a|$ Lateral view of $\beta$-galactosidase expression in a wildtype embryo carrying the en-lacZ gene is in the posterior compartment of the epidermis (arrowhead) and in the posterior region of the CNS /not visible in this focal plane) in each segment. The bracket indicates the part of the segment that does not express $\beta$-galactosidase, except for the small, mid-lateral protrusion corresponding to the tracheal pit. The arrow indicates $\beta$-galactosidase expression in the posterior compartment of the labial lobe. (b) Lateral view of $\beta$-galactosidase expression in a $\mathrm{ph}^{-}$; en$l a c Z$ embryo. The arrowhead indicates residual $\beta$ galactosidase from the early, normal en-lacZ expression in the posterior compartment whereas the bracket indicates the faint, but detectable, ectopic expression in the anterior compartment. The arrow indicates the high level of ectopic expression in the head segments. (c) Expression in a $f t z-l a c Z$ embryo at $6 \mathrm{hr}$ of development at the extended germ-band stage; the arrowhead points to one of the seven epidermal stripes; and the arrow indicates one pair of MP2s. It is not possible to distinguish wild-type from $\mathrm{ph}^{-}$embryos at this stage. (d) Expression in a wild-type embryo at $13 \mathrm{hr}$; the arrow indicates the progeny of the MP2s. The native $f t z$ protein is not found in embryos of this stage, but there is perdurance of lacZ. $|e|$ Expression in a $\mathrm{ph}^{-}$; $\mathrm{ftz}-\mathrm{lacZ} \mathrm{em}-$ bryo. The arrows indicate pairs of MP2s that have not divided but continue to label with $\beta$-galactosidase.

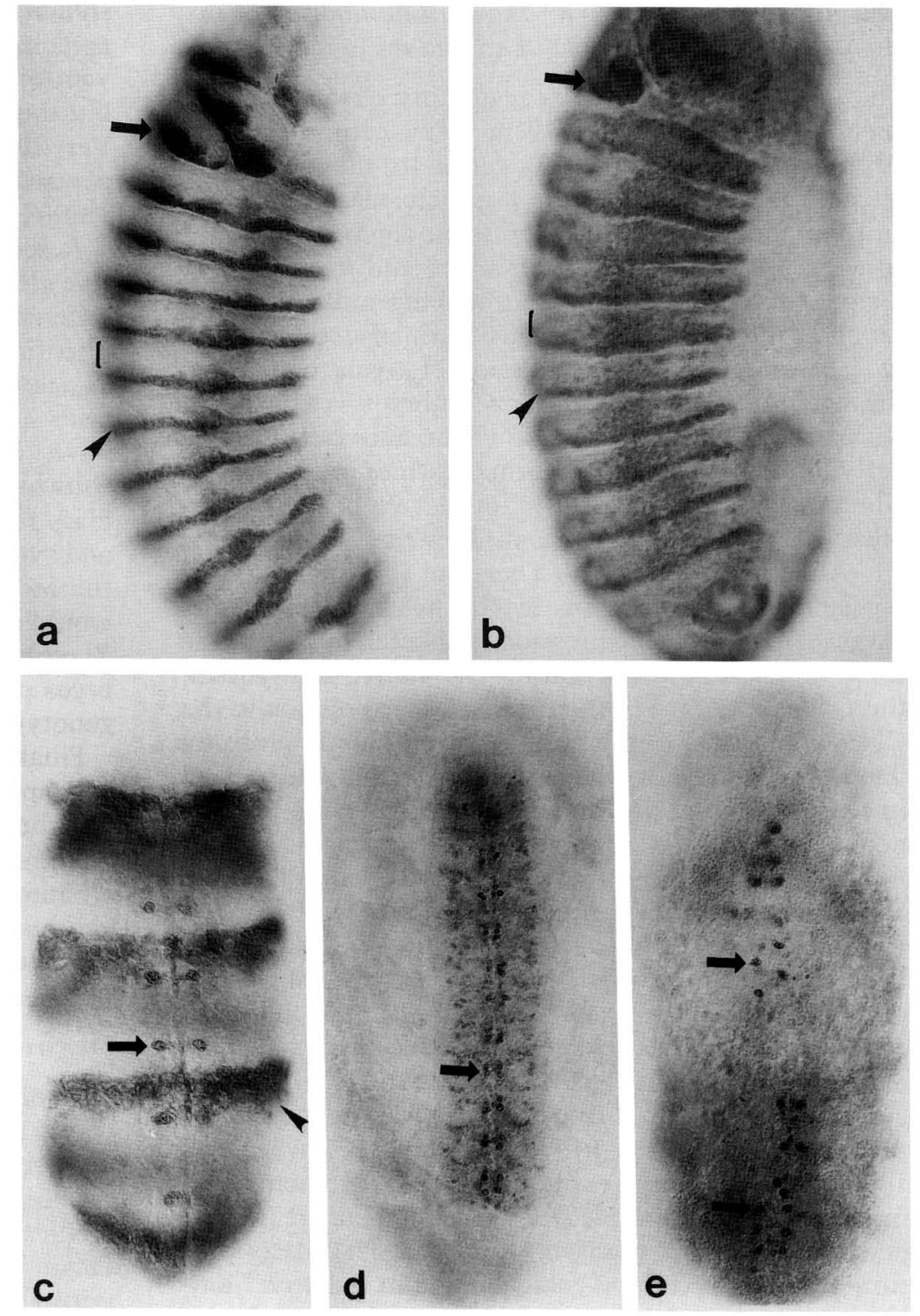

The CNS axons of $p h^{-}$embryos fail to form commissures or connectives and instead form large bundles in the middle of each hemiganglion. It appears that an intrinsic or extrinsic factor required for CNS growth cones to leave the hemiganglion of birth and to migrate along the stereotyped axonal pathways characteristic of the wild-type nervous system is missing in $p h^{-}$mutants. It is possible that this missing factor is an extrinsic growth factor or an unidentified substrate, such as some component of the glia (Bastiani and Goodman 1987), which is required for pathfinding by the initial, pioneer neurons (Bate 1976). It is also possible that the $p h$ mutation affects an intrinsic property of the CNS cells, such as neuronal identity, which is required for normal axon elongation or guidance. However, it seems unlikely that the bundles are the result of a trivial defect in axon structure, because preliminary transmission electron micros- copy of $\mathrm{ph}^{-}$embryos indicates that the short CNS axons that are produced are normal in subcellular morphology, produce normal filopodia, and, in some cases, are able to fasciculate within the bundle, though not necessarily with normal partners. Furthermore, sensory cell axons are able to elongate and, in some instances, pioneer nearly normal dorsoventral pathways to the CNS, suggesting that the defect does not simply prevent axon elongation.

The effects of $p h$ mutations on the patterns of expression of homeotic genes differ significantly from the effects of other members of the Pc group. Pc and extra sex combs $(e s c)$ seem to be required for the maintenance, but not the initiation, of expression of $U b x$ and Antp in the epidermis and the CNS. Loss of gene activity of either of these loci results in initially high levels of $U b x$ and Antp expression in the epidermis and CNS of all 
segments, which then decline to low levels of expression in a repeated pattern in all segments of the CNS (White and Wilcox 1984, 1985a; Beachy et al. 1985; Struhl and Akam 1985; Struhl and White 1985; Carroll et al. 1986; Wedeen et al. 1986). There appears to be no effect on $U b x$ or Scr gene expression in the epidermis prior to the onset of germ-band retraction in $p^{-}$embryos. Following germ-band retraction, $p h^{-}$embryos show ectopic expression of $U b x$ in the epidermis of segments $\mathrm{Tl}-\mathrm{A} 7$, and the levels of expression are low and uniform in all of the affected segments. Loss of $p h$ gene activity causes ectopic expression of $S c r$ in the epidermis of one or two segments anterior to labial lobe, the segment normally expressing Scr. This expression could indicate transformation of segmental identity of the presumptive mandibular and maxillary lobes, which could, in turn, cause the abnormal shape of the heads of $p h^{-}$embryos. Finally, loss of $p h$ gene activity causes the complete suppression of $U b x, A n t p$, and $S c r$ gene expression in the CNS by $10 \mathrm{hr}$ of development; at this same stage, $P c$ mutations cause high levels of ectopic homeotic gene expression in the CNS (Wedeen et al. 1986). These results indicate that $p h$ gene activity is required for the maintenance of the normal patterns of homeotic gene expression in the epidermis and for initiation of those patterns in the CNS. They also indicate that the $P c$ group, despite the apparent similarity in members in some aspects of phenotype, consists of a diverse set of genes with multiple and overlapping functions. Part of these observed differences may reflect differing contributions of maternally and zygotically derived gene products, as many of these genes have been shown to be maternally expressed (Struhl 1981; Haynie 1983; Breen and Duncan 1986; this paper).

The early epidermal patterns of expression of the three segmentation genes examined are normal in $\mathrm{ph}^{-} \mathrm{em}-$ bryos, yet the later patterns of expression of all three are affected by loss of $p h$; these effects are quite complex in gene- and tissue-specific ways. en is not expressed normally in the CNS in $p h^{-}$embryos, yet it is expressed ectopically in the anterior compartments of all thoracic and abdominal segments and in some of the head segments. This would imply that $p h^{+}$is required for establishing and maintaining the normal pattern of expression in the CNS and for suppressing en synthesis in the anterior epidermal compartment. There is a loss of $f t z$ expression in the CNS as well, yet eve is expressed ectopically throughout much of the CNS. The latter result rules out the possibility that the loss of homeotic and segmentation gene expression is simply caused by sickness or death of the CNS cells or by a general inability of these cells to support gene expression. Rather, it suggests that $p h$ is required for normal patterns of CNS gene expression and that the homeotic and segmentation genes are regulated by different mechanisms at different times and in different tissues during development.

The early epidermal patterns of $e n-l a c Z$ and $f t z-l a c Z$ expression are normal in $\mathrm{ph}^{-}$embryos, which is consistent with the early normal patterns of native protein expression. The pattern of ectopic expression of en-lacZ in the epidermis parallels that of the native protein, and in this case, at least, it may be concluded that en is regulated directly or indirectly by $p h$ at the level of transcription. In the CNS, however, the interpretation is complicated by perdurance of $l a c Z$ synthesized at an earlier stage. Although $f t z$ protein does not appear to be synthesized in the CNS of $p h^{-}$embryos, lacZ expression occurs in one pair of neuronal precursor cells that normally express $f t z$ (Fig. 7). The inability to detect the native $f t z$ protein in the MP2s may be due to the relatively lower sensitivity of the $f t z$ antisera compared with the $\beta$-galactosidase antisera, or to the transient nature of $f t z$ relative to $\beta$-galactosidase. The $\beta$-galactosidase expression in the MP2s occurs in every segment and thus cannot be due to perdurance from the stripe expression, which occurs in every other segment. Thus, it may indicate that regulation of $p h$ is at some level of gene expression other than transcription, that $\mathrm{ftz}$ is regulated in a different and $p h$-independent way in the MP2s, or that there is sufficient perdurance of maternal ph gene product to initiate $f t z$ expression in these cells, which are among the first in the CNS to express it normally. It can be concluded from this expression, however, that at least some of the neuronal precursors are born in normal locations and at normal times during neurogenesis in $p h^{-}$embryos.

Taken together, these data suggest an intriguing explanation for the axonal phenotype of $p h^{-}$embryos. Loss of homeotic and segmentation gene expression could result in a drastic loss or change in neuronal cell identity, which could, in turn, result in the inability of neurons to pioneer and follow their appropriate axon pathways. There is precedent for this because it has been shown that at least some of the neurons that express $f t z$ (Doe et al. 1988a) and eve (Doe et al. 1988b) require those genes for proper axon morphology.

These results are also consistent with the theory that the loss of $p h$ indirectly causes the CNS phenotype. Thus, it is possible that ph regulates some gene (or genes), as yet unidentified and distinct from the homeotic and segmentation genes, that is required for normal axonal guidance. It is also possible that $p h$ is required for the survival of some cell type other than the ventral epidermis and that loss of these cells results in the axon bundles.

Although the formation of the axon bundles is a remarkable phenotype, it is not without precedent. Probst (1901) described an inherited disorder of mammals in which axons of the corpus callosum fail to connect the cerebral hemispheres and instead form large whorls or neuromas, termed Probst's bundles. Silver et al. (1982) have demonstrated that the callosal commissures normally grow over a glial bridge connecting the hemispheres and the loss of this bridge, either surgically or genetically in the case of the acallosal mutants, causes the formation of the probst's bundles. Reimplantation of the glial bridge partially rescues the surgically induced acallosal defect (Silver and Ogawa 1983). The similarity between Probst's bundles and the bundles formed in $\mathrm{ph}^{-}$ embryos is striking, and, indeed, a major component of 
the embryonic glia is missing in $p h^{-}$mutants. It remains to be seen whether these glial cells die or are transformed during the development of $p^{-}$embryos and what role, if any, they play in generating the normal commissures of the Drosophila embryonic nervous system.

\section{Experimental procedures}

\section{Strains}

Flies were raised on standard media at $25^{\circ} \mathrm{C}$, and embryos were collected on grape juice agar plates at 18 or $25^{\circ} \mathrm{C}$ and aged appropriately. The double mutant $1(1) p h^{505}$ was obtained from J.-M. Dura; the en-lacZ strain was a gift from C. Hama and T. Kornberg; the $f t z-l a c Z$ strain was a gift from Y. Hiromi. Df(1)IA52 (Perrimon et al. 1985) has been described previously.

\section{Analysis of germ-line clones}

Female flies of the genotype $y p h^{505}$ f/FM7 were mated to males carrying the $\mathrm{X}$-linked dominant female sterile mutation Fs(1)K1237 (or ovo ${ }^{D 1}$ ) (Perrimon et al. 1984). Progeny were irradiated at the first larval instar stage with a constant dose of 1000 rads (Torrex 120D; $100 \mathrm{kv}, 5 \mathrm{~mA}$ ) to generate homozygous $p h^{505}$ clones in the germ line.

\section{Embryo morphology}

First instar larval cuticles were prepared from 24-hr-old egg collections, using Hoyer's mounting technique of van der Meer (1977), and were photographed using phase-contrast microscopy. Histological sections of embryos were prepared as described by Mahowald et al. (1979); embryos were prepared for scanning (Turner and Mahowald 1976) and transmission electron microscopy using published protocols.

\section{Immunohistochemistry}

Immunolocalization was performed on whole embryos using minor modifications of published procedures (Mitchison and Sedat 1983). Embryos were dechorionated in 50\% Clorox bleach, fixed for $25 \mathrm{~min}$ in phosphate-buffered saline (PBS)-buffered $4 \%$ paraformaldehyde/heptane, and devitellinized with absolute methanol; all steps were performed at room temperature. Embryos were washed in PBS plus $0.1 \%$ Triton X-100 (PT) and incubated with primary antibody overnight at $4{ }^{\circ} \mathrm{C}$. Embryos were then washed in PT, blocked in PT plus $2 \%$ normal goat serum, and incubated with goat anti-mouse IgMAG or goat anti-rabbit IgG conjugated to either fluorescein or HRP. Histochemical localization of HRP was performed as published (Ghysen et al. 1986), after which embryos were dehydrated in ethanol, cleared in methylsalicylate, and viewed with a Nikon microscope with Nomarski optics. Fluorescently labeled embryos were cleared in $90 \%$ glycerol plus $2 \% n$-propylgallate (Giloh and Sedat 1982) and viewed with a Zeiss epifluorescence microscope. All secondary antibodies, as well as fluoresceinconjugated goat anti-HRP, were obtained from Cappel.

\section{Acknowledgments}

The authors wish to thank the following people for the use of antibodies: Allan Bieber, Sean Carroll, Steve DiNardo, Chris Doe, C.Q., D. Smouse, and C.S. Goodman. 1988b. Control of Patel, Peter Riley, Matthew Scott, and Robert White. We are grateful to C. Hama, Thomas Kornberg, Yasushi Hiromi, JeanMaurice Dura, and the Bowling Green Stock Center for suppling fly stocks, to Ken Burtis and Kai Zinn for reading the manuscript, and to Roger Jacobs and Kari Maier for help with the electron microscopy. We thank J.-M. Dura for comments on our results prior to production. We are especially grateful to Chris Doe and Linda Ambrosio for critically reading the manuscript and for many helpful discussions. This work was supported by grants from the National Institutes of Health (NIH) and the National Institute of Mental Health to C.S.G., by a grant from the American Cancer Society to N.P., and by an NIH Postdoctoral Fellowship to D.S.; N.P. was a Lucille P. Markey scholar.

\section{References}

Akam, M. 1987. The molecular basis for metameric pattern in the Drosophila embryo. Development 101: 1-22.

Bastiani, M.J. and C.S. Goodman. 1987. Guidance of neuronal growth cones in the grasshopper embryo. III. Recognition of specific glial pathways. I. Neurosci. 6: 3542-3551.

Bate, C.M. 1976. Pioneer neurons in an insect embryo. Nature 260: $54-56$.

Baumgartner, S., D. Bopp, M. Burri, and M. Noll. 1987. Structure of two genes at the gooseberry locus related to the paired gene and their spatial expression during Drosophila embryogenesis. Genes Dev. 1: 1247-1267.

Beachy, P.A., S.L. Helfand, and D.S. Hogness. 1985. Segmental distribution of bithorax complex proteins during Drosophila development. Nature 313: 545-551.

Breen, T.R. and I.M. Duncan. 1986. Maternal expression of genes that regulate the bithorax complex of Drosophila melanogaster. Dev. Biol. 118: 442-456.

Campos-Ortega, J.A. and V. Hartenstein. 1985. The embryonic development of Drosophila melanogaster. Springer-Verlag, New York.

Carroll, S.B. and M.P. Scott. 1985. Localization of the fushi tarazu protein during Drosophila embryogenesis. Cell 43: 47-57.

Carroll, S.B., R.A. Laymon, M.A. McCutcheon, P.D. Riley, and M.P. Scott. 1986. The localization and regulation of Antennapedia protein expression in Drosophila embryos. Cell 47: $113-122$.

Coleman, K.G., S.J. Poole, M.P. Weir, W.C. Soeller, and T. Kornberg. 1987. The invected gene of Drosophila: Sequence analysis and expression studies reveal a close kinship to the engrailed gene. Genes Dev 1: 19-28.

Denell, R.E. 1978. Homeosis in Drosophila. II. A genetic analysis of Polycomb. Genetics 90: 277-289.

DiNardo, S., J.M. Kuner, J. Theis, and P.H. O'Farrell. 1985. Development of embryonic pattern in D. melanogaster as revealed by accumulation of the nuclear engrailed protein. Cell 43: 59-69.

Doe, C.Q. and C.S. Goodman. 1985a. Early events in insect neurogenesis. I. Developmental and segmental differences in the pattern of neuronal precursor cells. Dev. Biol. 111: 193-205.

-1985b. Early events in insect neurogenesis. II. The role of cell interactions and cell lineage in the determination of neuronal precursor cells. Dev. Biol. 111: 206-219.

Doe, C.Q., Y. Hiromi, W.J. Gehring, and C.S. Goodman. 1988a. Expression and function of the segmentation gene fushi tarazu during Drosophila neurogenesis. Science 239: 170175.

Doe, C.Q., D. Smouse, and C.S. Goodman. 1988b. Control of 
neuronal fate by the Drosophila segmentation gene evenskipped. Nature 333: 376-378.

Duncan, I.M. 1982. Polycomblike: A gene that appears to be required for the normal expression of the Bithorax and Antennapedia gene complexes of Drosophila melanogaster. Genetics 102: 49-70.

Dura, I.-M., H.W. Brock, and P. Santamaria. 1985. Polyhomeotic: A gene of Drosophila melanogaster required for correct expression of segmental identity. Mol. Gen. Genet. 198: $213-220$.

Dura, J.-M., N.B. Randsholt, J. Deatrick, I. Erk, P. Santamaria, J.D. Freeman, S.J. Freeman, D. Weddell, and H.W. Brock. 1987. A complex genetic locus, polyhomeotic, is required for segmental specification and epidermal development in D. melanogaster. Cell 51: 829-839.

Frasch, M., T. Hoey, C. Rushlow, H. Doyle, and M. Levine. 1987. Characterization and localization of the even-skipped protein of Drosophila. EMBO J. 6: 749-759.

Garcia-Bellido, A. and E.B. Lewis. 1976. Autonomous cellular differentiation of homeotic bithorax mutants of Drosophila melanogaster. Dev. Biol. 48: 400-410.

Gergen, J.P. and E. Wieschaus. 1985. The localized requirements for a gene affecting segmentation in Drosophila: Analysis of larvae mosaic for runt. Dev. Biol. 109: 321-335.

- 1986. Localized requirements for gene activity in seg. mentation of Drosophila embryos: Analysis of armadillo, fused, giant and unpaired mutations in mosaic embryos. Wilhelm Roux's Arch. Dev. Biol. 195: 49-62.

Ghysen, A., C. Dambly-Chaudiere, E. Aceves, L.Y. Jan, and Y.N. Jan. 1986. Sensory neurons and peripheral pathways in Drosophila embryos. Wilhelm Roux's Arch. Dev. Biol. 195: $281-289$.

Giloh, H. and J.W. Sedat. 1982. Fluorescence microscopy; reduced photobleaching of rhodamine and fluorescin protein conjugates by n-propyl gallate. Science 217: 1252-1255.

Goodman, C.S., M.J. Bastiani, C.Q. Doe, S. du Lac, S.L. Helfand, J.Y. Kuwada, and J.B. Thomas. 1984. Cell recognition during neuronal development. Science 225: 1271-1279.

Haynie, J.L. 1983. The maternal and zygotic roles of the gene Polycomb in embryonic determination in Drosophila melanogaster. Dev. Biol. 100: 399-411.

Hiromi, Y. and W.J. Gehring. 1987. Regulation and function of the Drosophila segmentation gene fushi tarazu. Cell 50: $963-974$.

Jan, L.Y. and Y.N. Jan. 1982. Antibodies to horseradish peroxidase as specific neuronal markers in Drosophila and in grasshopper embryos. Proc. Natl. Acad. Sci. 79: 2700-2704.

Jürgens, G., E. Wieschaus, and C. Nüsslein-Volhard. 1984. Mutations affecting the pattern of the larval cuticle in Drosophila melanogaster. II. Zygotic loci on the third chromosome. Wilhelm Roux's Arch. Dev. Biol. 193: 283-295.

Jürgens, G. 1985. A group of genes controlling the spatial expression of the bithorax complex in Drosophila. Nature 316: $153-155$.

Kaufman, T.C. 1983. The genetic regulation of segmentation in Drosophila melanogaster. In Time, space, and pattern in embryonic development. (ed. W.R. Jeffrey and R.A. Raff), pp. 365-383. Alan R. Liss, New York.

Kuwada, J.Y. and C.S. Goodman. 1985. Neuronal determination during embryonic development of the grasshopper nervous system. Dev. Biol. 110: 114-126.

Lewis, E.B. 1978. A gene complex controlling segmentation in Drosophila. Nature 276: 565-570.

Mahowald, A.P., J.H. Caulton, and W.J. Gehring. 1979. Ultrastructural studies of oocytes and embryos derived from fe- male flies carrying the grandchildless mutation in Drosophila subobscura. Dev. Biol. 69: 118-132.

Mitchison, T.J. and J. Sedat. 1983. Localization of antigenic determinants in whole Drosophila embryos. Dev. Biol. 99: $261-264$.

Morata, G. and A. Garcia-Bellido. 1976. Developmental analysis of some mutants of the bithorax system of Drosophila. Wilhelm Roux's Arch. Dev. Biol. 179: 125-143.

Nüsslein-Volhard, C. and E. Wieschaus. 1980. Mutations affecting segment number and polarity in Drosophila. Nature 287: 795-801

Nüsslein-Volhard, C., E. Wieschaus, and H. Kluding. 1984. Mutations affecting the pattern of the larval cuticle in Drosophila melanogaster. I. Zygotic loci on the second chromosome. Wilhelm Roux's Arch. Dev. Biol. 193: 267-282.

Perrimon, N., L. Engstrom, and A.P. Mahowald. 1984. Developmental genetics of the $2 \mathrm{E}-\mathrm{F}$ region of the Drosophila $\mathrm{X}$ chromosome: A region rich in 'developmentally important' genes. Genetics 108: 559-572.

- 1985. Developmental genetics of the 2C-D region of the Drosophila X chromosome. Genetics 111: 23-41.

Probst, M. 1901. Uber den bau des balkenlosen grosshirns, sowie uber mikrogyrie und heterotopie der grauen substanz. Arch. Psychiatr. 34: 709-786.

Riley, P.D., S.B. Carroll, and M.P. Scott. 1987. The expression and regulation of Sex combs reduced protein in Drosophila embryos. Genes Dev. 1: 716-730.

Sato, T., P.H. Hayes, and R.E. Denell. 1985. Homoeosis in Drosophila: Roles and spatial patterns of expression of the $A n$ tennapedia and Sex combs reduced loci in embryogenesis. Dev. Biol. 111: 171-192.

Silver, J. and M.Y. Ogawa. 1983. Postnatally induced formation of the corpus callosum in acallosal mice on glia-coated cellulose bridges. Science 220: 1067-1069.

Silver, J., S.E. Lorenz, D. Wahlsten, and J. Coughlin. 1982. Axonal guidance during development of the great cerebral commissures: Descriptive and experimental studies, in vivo, on the role of preformed glial pathways. I. Comp. Neurol. 210: 10-29.

Snow, P.M., N.H. Patel, A.L. Harrelson, and C.S. Goodman. 1987. Neural-specific carbohydrate moiety shared by many surface glycoproteins in Drosophila and grasshopper embryos. J. Neurosci. 7: 4137-4144.

Struhl, G. 1981. A gene product required for correct initiation of segmental determination in Drosophila. Nature 293: 3641.

Struhl, G. and M. Akam. 1985. Altered distributions of Ultrabithorax transcripts in extra sex combs mutant embryos of Drosophila. EMBO \%. 4: 3259-3264.

Struhl, G. and R.A.H. White. 1985. Regulation of the Ultrabithorax gene of Drosophila by other bithorax complex genes. Cell 43: 507-519.

Thomas, J., M.J. Bastiani, C.M. Bate, and C.S. Goodman. 1984. From grasshopper to Drosophila: A common plan for neuronal development. Nature 318: 203-207.

Turner, F.R. and A.P. Mahowald. 1976. Scanning electron microscopy of Drosophila embryogenesis. I. The structure of the egg envelopes and the formation of the cellular blastoderm. Dev. Biol. 50: 95-108.

- 1979. Scanning electron microscopy of Drosophila melanogaster embryogenesis. III. Formation of the head and caudal segments. Dev. Biol. 68: 96-109.

Van der Meer, J.M. 1977. Optically clean and permanent whole mount preparation for phase-contrast microscopy of cuticular structures of insect larvae. Dros. Info. Serv. 52: 160

Villares, R. and C. Cabrera. 1987. The achaete-scute gene com- 
plex of $D$. melanogaster: Conserved domains in a subset of genes required for neurogenesis and their homology to myc. Cell 50: 415-424.

Wakimoto, B.T. and T.C. Kaufman. 1981. Analysis of larval segmentation in lethal genotypes associated with the Antennapedia gene complex in Drosophila melanogaster. Dev. Biol. 81: 51-64.

Wedeen, C., K. Harding, and M. Levine. 1986. Spatial regulation of Antennapedia and bithorax gene expression by the Polycomb locus in Drosophila. Cell 44: 739-748.

White, R.A.H. and M. Wilcox. 1984. Protein products of the bithorax complex in Drosophila. Cell 39: 163-171.

. 1985a. Regulation of the distribution of Ultrabithorax proteins in Drosophila. Nature 318: 563-567.

- 1985b. Distribution of Ultrabithorax proteins in Drosophila. EMBO f. 4: 2035-2043.

Wieschaus, E., C. Nüsslein-Volhard, and G. Jürgens. 1984. Mutations affecting the pattern of the larval cuticle in Drosophila melanogaster. III. Zygotic loci on the X chromosome and fourth chromosome. Wilhelm Roux's Arch. Dev. Biol. 193: 296-307.

Wirz, J., L.I. Fessler, and W.J. Gehring. 1986. Localization of the Antennapedia protein in Drosophila embryos and imaginal discs. EMBO I. 5: 3327-3334. 


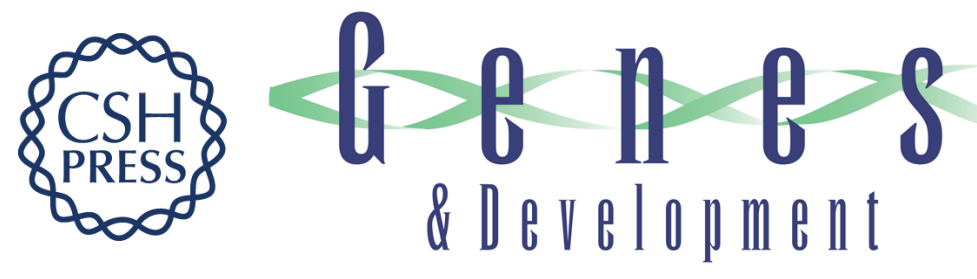

\section{polyhomeotic: a gene required for the embryonic development of axon pathways in the central nervous system of Drosophila.}

D Smouse, C Goodman, A Mahowald, et al.

Genes Dev. 1988, 2:

Access the most recent version at doi:10.1101/gad.2.7.830

References This article cites 60 articles, 13 of which can be accessed free at:

http://genesdev.cshlp.org/content/2/7/830.full.html\#ref-list-1

License

Email Alerting

Service

Receive free email alerts when new articles cite this article - sign up in the box at the top right corner of the article or click here.

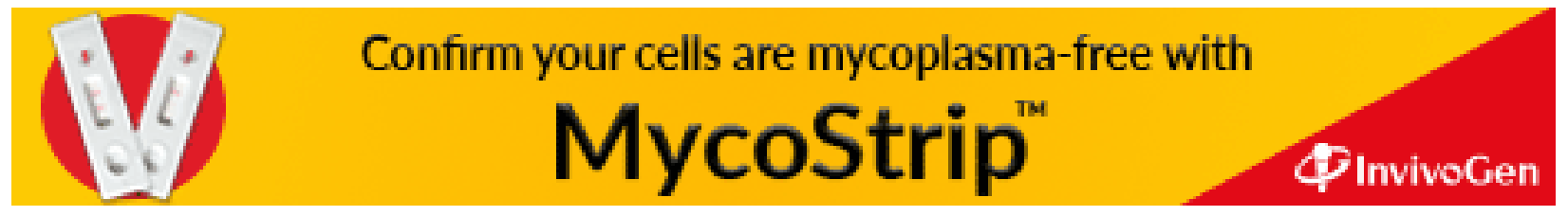

